\section{'Mimi' Sweet Pea for Forcing Culture}

\author{
Kaoru Nakamura ${ }^{1}$, Hirotoshi Hino, Sadao Gunji, Norio Hattanda, \\ Toshio Murata, Hiroshi Tominaga, and Koichi Fukumoto
}

Floriculture Division, Miyazaki Agricultural Research Institute, Shimonaka 5805, Sadowara Miyazaki, 8800211, Japan

\section{Ryo Akashi \\ Frontier Science Research Center, University of Miyazaki, Kibanadainishi Miyazaki, Japan}

Additional index words. Lathyrus odoratus, cultivar, cut flower, ornamental breeding

Abstract. 'Mimi' sweet pea (Lathyrus odoratus L.) is a new cultivar in Japan, released by the Miyazaki Agricultural Research Institute. Sweet pea is grown by forcing culture in Japan for cut flower production. As a cut flower, sweet pea is very popular and is marketed from November to April. 'Mimi' produces $145 \%$ more marketable flowers than the main pink cultivar, Super Rose. 'Mimi' also has several desirable qualities as a cut flower. The flower color is strong pink. It is as brilliant under fluorescent lights indoors as it is in the field.

The sweet pea (Lathyrus odoratus L.) was discovered in Sicily in 1695 (Rice, 2002). Many cultivars have been bred in England and the United States since its introduction in England.

Sweet pea cultivation is popular not only in the United Kingdom and the United States, but also in Europe, Russia, Egypt, New Zealand, Australia, and Japan (Hambidge, 1996; Inoue, 1981, 2007; Rice, 2002). There are some reports of commercial sweet pea cut flower production (Hammett, 2006; Inoue, 1981; Parsons, 2004). However, the quantity of cut flower production worldwide is unknown because there are no statistics available. The majority of sweet pea seed is produced by California in the United States and by New Zealand (Hambidge, 1996; Inoue, 1981, 2007; Rice, 2002).

The date when the sweet pea was introduced in Japan is unclear, but commercial culture started in 1929 (Inoue, 2007). In 2004 , the value of sweet pea cut flower production in Japan was $\approx \$ 27$ million U.S. (JPN $¥ 2.9$ billion) (Japan Flower Promotion Center, 2004). The sweet pea is a very popular cut flower in Japan and is marketed from November to April. It is a major cut flower crop and is grown to meet the demand.

The sweet pea has three flowering types: winter, spring, and summer (Inoue, 2002). In Japan, most growers grow cultivars of the winter and spring flowering types because cultivars of both types require cold storage of germinated seed for vernalization to induce flowering from November. Cultivars of the summer flowering type, however, also need long-day treatment to induce flowering.

Most Japanese growers maintain their own seed by heritage seed production

Received for publication 30 June 2008. Accepted for publication 16 Sept. 2008

${ }^{1}$ To whom reprint requests should be addressed; e-mail nakamura-kaoru@pref.miyazaki.lg.jp because imported commercial seed does not have stabilized flowering types or flower colors when grown in Japan. Most cultivars grown in Japan have been selected and established from imported market seed by Japanese growers.

The Miyazaki Agricultural Research Institute is situated in Miyazaki prefecture, the biggest sweet pea cut flower production region in Japan. To promote sweet pea production in Miyazaki prefecture, we are trying to breed new cultivars that have desirable qualities and yield. 'Mimi' sweet pea, shown in Figure 1, a new cultivar with desirable qualities and high yield, is reported here.

\section{Origin}

'Mimi' was derived from a cross between 'Stella' (female), a spring flowering type with cream flower color, and 'Early Salmon Pink'

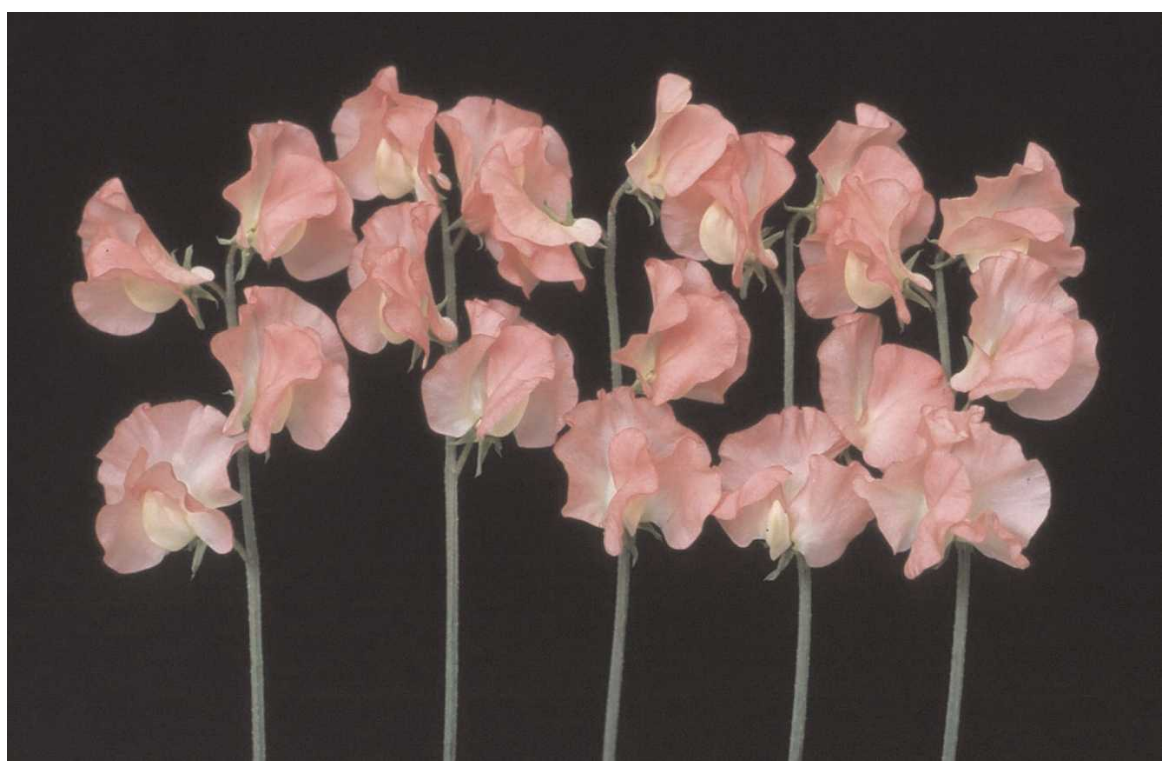

Fig. 1. Flowers of 'Mimi' sweet pea. (male), a winter flowering type with a strong pink flower color, in a greenhouse at the Floriculture Division, Miyazaki Agricultural Research Institute, Japan, in Spring 1998 as shown in Figure 2.

The $F_{1}$ was selfed in Spring 1999 to produce $F_{2}$ seed. Pedigree selection was made from $\mathrm{F}_{2}$ to $\mathrm{F}_{6}$. Selection was based on cut flower yield and cut flower qualities such as density of inflorescence, flower color, and length of peduncle.

\section{Description}

The test was performed with control cultivars Super Rose and Stella at Miyazaki Agricultural Research Institute. The first fully opened bloom, cut flower yield, and budding time of nonvernalized plants were analyzed in 2004. Morphological characteristics were studied in 2007. The cultural practices were the same each year.

Germinated seeds were vernalized by cold storage in the dark at $2{ }^{\circ} \mathrm{C}$ for 4 weeks. Seeds were planted in the greenhouse on 10 Sept. after vernalization. The distance between rows was $100 \mathrm{~cm}$, and intrarow spacing was $12 \mathrm{~cm}$. The planting rate was 8333 plants $/ 1000 \mathrm{~m}^{2}$. Plants were grown on the normal single-stem cordon system. Minimum temperature was maintained at $5{ }^{\circ} \mathrm{C}$ through the growing season until 31 Mar. The amount of basal fertilizer was $10 \mathrm{~N}-10 \mathrm{P}-$ $10 \mathrm{~K} \mathrm{~kg} \cdot 1000 \mathrm{~m}^{-2}$

Flower. The flower form is open (Table 1) according to Beal (Beal, 1914). The average flower diameter is $5.8 \mathrm{~cm}$. There is no variegation on the petals. The number of standard petals is one and wing petals are two. Both standard and wings are the same color, strong pink (48C) according to the Royal Horticultural Color Chart (Royal Horticultural Society, 2001).

The standard form is entire, $4.5 \mathrm{~cm}$ long and $5.8 \mathrm{~cm}$ wide. The wings are moderately 
incurved, $3.9 \mathrm{~cm}$ long, and $3.2 \mathrm{~cm}$ wide. The keel is $2.7 \mathrm{~cm}$ long and $1.5 \mathrm{~cm}$ wide. Pistil is present. Calyx is campanulate and not pigmented.

The density of inflorescence is 3.8 flowers on an inflorescence, a suitable number for cut flower production. The flower direction is upward.

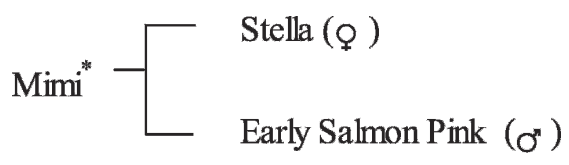

\section{${ }^{*} \mathrm{~F}_{2}-\mathrm{F}_{6}$ Pedigree Selection}

Fig. 2. Pedigree of 'Mimi' sweet pea.

Table 1. Characteristics of 'Mimi' and control cultivars at Miyazaki Agricultural Research Institute (2007 to 2008).

\begin{tabular}{|c|c|c|c|c|c|c|c|c|}
\hline \multirow[b]{2}{*}{ Cultivar } & \multicolumn{2}{|r|}{ Plant } & \multicolumn{6}{|c|}{ Flower } \\
\hline & $\begin{array}{l}\text { Plant } \\
\text { type }^{z}\end{array}$ & $\begin{array}{l}\text { Length of } \\
\text { internode }^{y} \\
(\mathrm{~cm})\end{array}$ & $\begin{array}{l}\text { Flower } \\
\text { form }^{\mathrm{x}}\end{array}$ & $\begin{array}{l}\text { Flower } \\
\text { diam. }^{w} \\
(\mathrm{~cm})\end{array}$ & $\begin{array}{l}\text { Flower color } \\
\text { RHS color } \\
\text { chart number }\end{array}$ & $\begin{array}{l}\text { Length of } \\
\text { peduncle }^{w} \\
\quad(\mathrm{~cm})\end{array}$ & $\begin{array}{c}\text { Density of } \\
\text { inflorescence }^{\mathrm{w}} \\
\text { (flowers) }\end{array}$ & $\begin{array}{c}\text { Flowering } \\
\text { type }\end{array}$ \\
\hline $\begin{array}{l}\text { Super } \\
\text { Rose }\end{array}$ & Tall & $7.9 \mathrm{a}$ & Open & $5.7 \mathrm{a}$ & $\begin{array}{l}\text { Strong purplish } \\
\text { pink N66D }\end{array}$ & $41.9 \mathrm{a}$ & $3.3 \mathrm{a}$ & Spring \\
\hline Stella & Tall & $7.6 \mathrm{a}$ & Open & $5.7 \mathrm{a}$ & Cream 11D & $40.9 \mathrm{a}$ & $3.9 \mathrm{~b}$ & Spring \\
\hline Mimi & Tall & $10.3 \mathrm{a}$ & Open & $5.8 \mathrm{a}$ & Strong pink $48 \mathrm{C}$ & $42.9 \mathrm{a}$ & $3.8 \mathrm{~b}$ & Spring \\
\hline
\end{tabular}

${ }^{2}$ Height at the 15th node. Dwarf: less than $40 \mathrm{~cm}$; intermediate: 40 to $70 \mathrm{~cm}$; tall: greater than $70 \mathrm{~cm}$.

y Internode under the node of first fully opened bloom. Values are means of two replications with 10 to 15 plants. Mean separation within column by Bonferroni's test, $P \leq 0.05$.

${ }^{\mathrm{x}}$ According to the classification by Beal (Beal, 1914).

wValues are means of two replications with inflorescences that bloomed in March. Mean separation within column by Bonferroni's test $(P \leq 0.05)$.

RHS $=$ Royal Horticultural Society.

Table 2. Date of first fully opened bloom and cut flower yield of 'Mimi' and control cultivars ${ }^{\mathrm{z}}$ (2004 to 2005).

\begin{tabular}{|c|c|c|c|c|}
\hline \multirow[b]{2}{*}{ Cultivar } & \multirow{2}{*}{$\begin{array}{c}\text { Date of first } \\
\text { fully opened bloom }\end{array}$} & \multicolumn{3}{|c|}{ Cut flower yield ${ }^{\mathrm{w}}$ (cut flowers/plant) } \\
\hline & & Total & Marketable $^{y}$ & '4P2L'x \\
\hline Super Rose & 17 Nov. a & $27.8 \mathrm{a}$ & $20.6 \mathrm{a}$ & $12.2 \mathrm{a}$ \\
\hline Stella & 11 Nov. a & $32.4 \mathrm{ab}$ & $28.2 \mathrm{~b}$ & $7.6 \mathrm{a}$ \\
\hline Mimi & 12 Nov. a & $35.7 \mathrm{~b}$ & $29.9 \mathrm{~b}$ & $12.9 \mathrm{a}$ \\
\hline
\end{tabular}

${ }^{\mathrm{z}}$ After 4 weeks of seed cold storage at $2{ }^{\circ} \mathrm{C}$ in darkness, direct sowed at 10 Sept. 2004.

${ }^{\mathrm{y}}$ Standard of shipment: the number of flowers is over three with peduncle from base to lowest flower is over $20 \mathrm{~cm}$.

${ }^{\mathrm{x}}$ The best category standard of shipment: the number of flowers is over four with peduncle from base to lowest flower is over $35 \mathrm{~cm}$.

${ }^{w}$ Average of two replications with three to 10 plants. Mean separation within columns by Bonferroni's test $(P \leq 0.05)$.
Flowering type. The flowering type is spring.

First fully opened bloom and cut flower yield. Flower budding occurred on 13 Oct. with 11 nodes. The first fully opened bloom was observed on 12 Nov., the same as 'Super Rose' and 'Stella' (Table 2). The cut flower yield was 35.7 flowers/plant, including 29.9 marketable flowers. It was higher than 'Super Rose'. The yield of the best category, "4P2L" (number of florets more than four with peduncle more than $35 \mathrm{~cm}$ long from the base of the peduncle to the lowest floret), was the same as 'Super Rose' and 'Stella'. The budding time of nonvernalized plants occurred on 31 Mar. with 83 nodes, therefore yielding no cut flowers until the end of March.

Use. 'Mimi' performs well when arranged in vases and bouquets. Its flower color is strong pink. It is as brilliant under fluorescent lights indoors as it is in the field.

\section{Literature Cited}

Beal, A.C. 1914. Sweet-pea studies, IV. Classification of garden varieties of the sweet pea. Bul. Cornell Univ. Coll. Agr. 342:213-360.

Hambidge, C. 1996. The unwins book of sweet pea Silent Books, Cambridge, UK.

Hammett, K. 2006. Pilgrimages. Natl. Sweet Pea Soc. Annu. 2006:87-89.

Inoue, T. 1981. Shonan no Sweet Pea. Shonan Onshitsu Kumiai, Samukawa, Japan [in Japanese]

Inoue, T. 2002. Effects of seed vernalization and photoperiod on flower bud initiation of summer, spring, and winter flowering types of sweet pea (Lathyrus odoratus L.). J. Jpn. Soc. Hort. Sci. 71:127-132 [in Japanese literature with English abstract].

Inoue, T. 2007. Sweet Pea wo Tsukurikonasu. Nohsangyoson Bunka Kyokai, Tokyo, Japan [in Japanese].

Japan Flower Promotion Center. 2004. Flower data book 2004. Japan Flower Promotion Center, Tokyo, Japan.

Parsons, R. 2004. Could you grow 55,000 cordons per year? Natl. Sweet Pea Soc. Annu. 2004: 104-114.

Rice, G. 2002. The sweet pea book. B T Batsford, London, UK.

Royal Horticultural Society. 2001. RHS colour chart. Royal Hort. Soc., London, UK. 